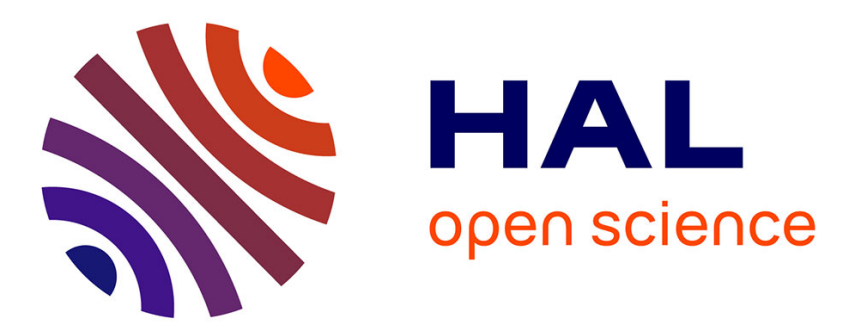

\title{
Microscopic Modelling of the Non-Linear Gap Junction Channels
}

\author{
Anđela Davidović, Yves Coudière, Thomas Desplantez, Clair Poignard
}

\section{To cite this version:}

Anđela Davidović, Yves Coudière, Thomas Desplantez, Clair Poignard. Microscopic Modelling of the Non-Linear Gap Junction Channels. 2015 Computing in Cardiology Conference, Sep 2015, Nice, France. hal-01418665

\section{HAL Id: hal-01418665 \\ https://hal.inria.fr/hal-01418665}

Submitted on 16 Dec 2016

HAL is a multi-disciplinary open access archive for the deposit and dissemination of scientific research documents, whether they are published or not. The documents may come from teaching and research institutions in France or abroad, or from public or private research centers.
L'archive ouverte pluridisciplinaire HAL, est destinée au dépôt et à la diffusion de documents scientifiques de niveau recherche, publiés ou non, émanant des établissements d'enseignement et de recherche français ou étrangers, des laboratoires publics ou privés. 


\section{On Gap Junctions}

- What is a Gap Junction?

- Cluster of gap junction channels

- Linking structure between neighbouring cells

- Provides direct passage of molecules and ions

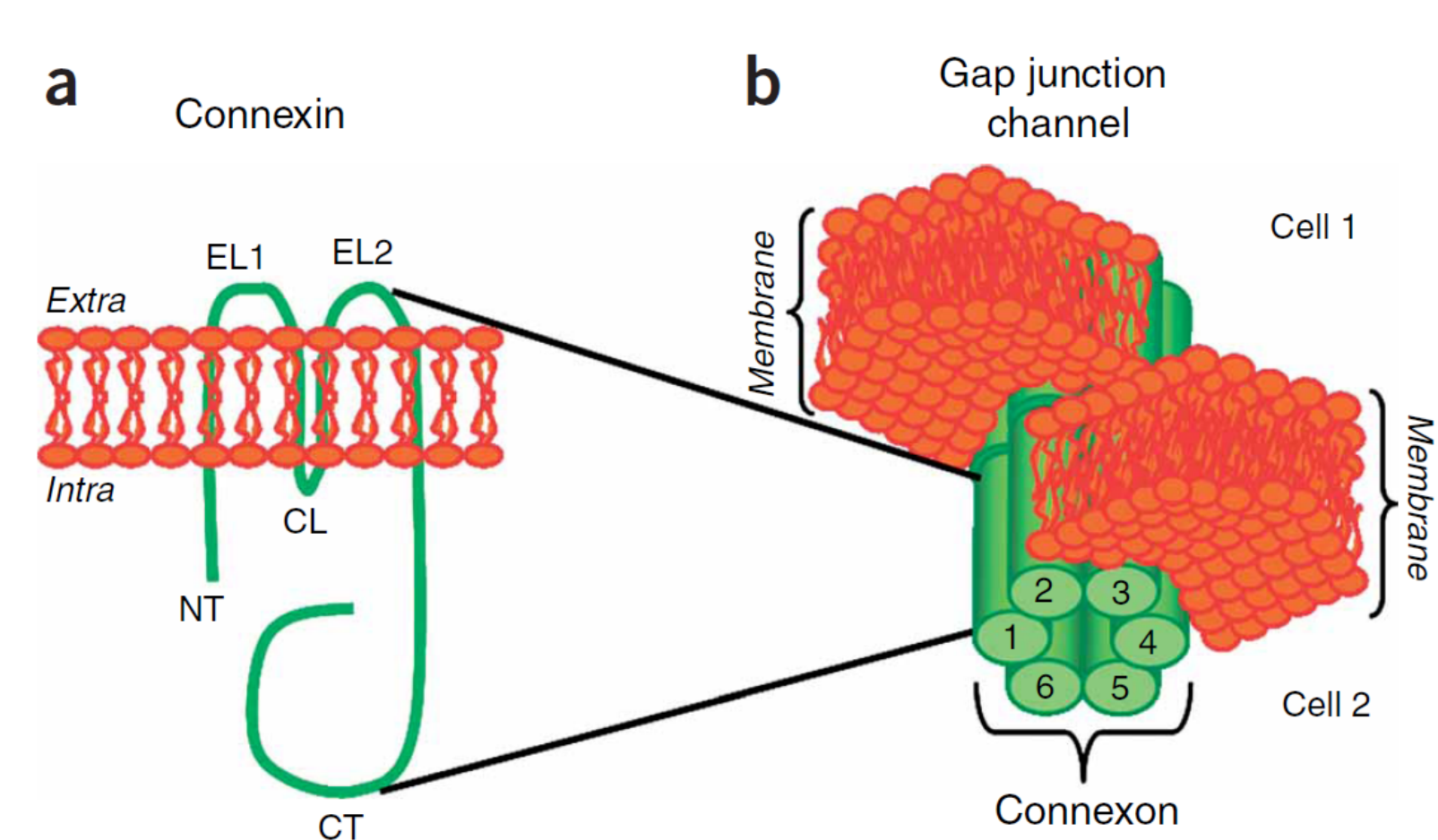

Figure: Schematic diagrams of a standard connexin molecule and gap junction channel. (Del Corso et. al., 2006)

- What are they made of?

- Proteins connexins.

- 6 connexins $=1$ connexon (hemichannel)

- 2 connexons $=1$ gap junction channel

- Cardiac cell proteins: Cx43, Cx45 and Cx40.

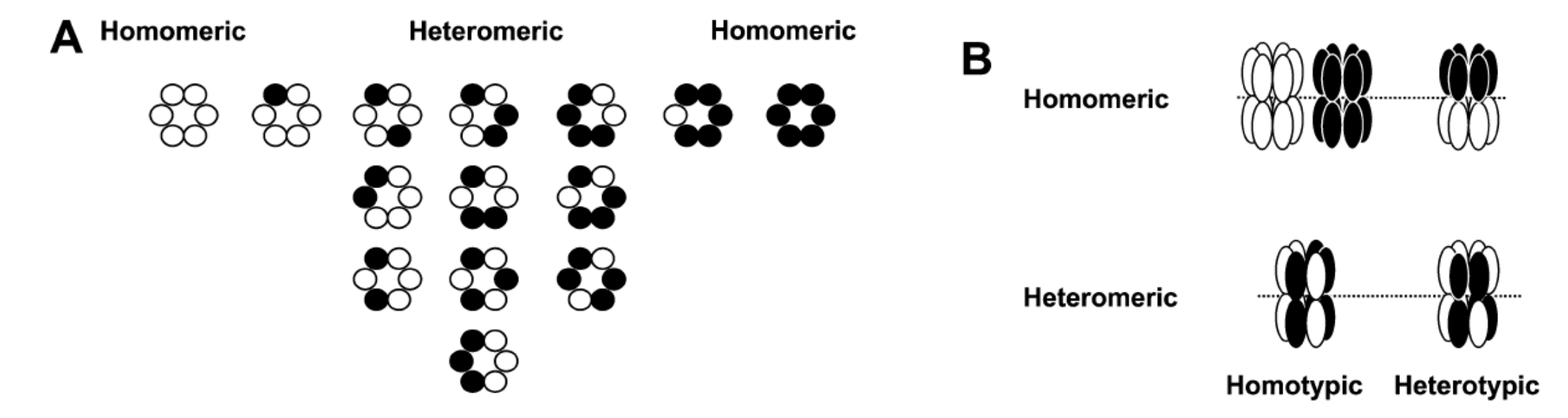

Figure: Predicted configurations of connexons and gap junction channels for two different connexins. (Desplantez, 2004)

- Where are they located in cardiac cells?

- Mostly on the longitudinal ends where they compose the intercalated disks

- The behaviour of transversal GJ channels is not well understood

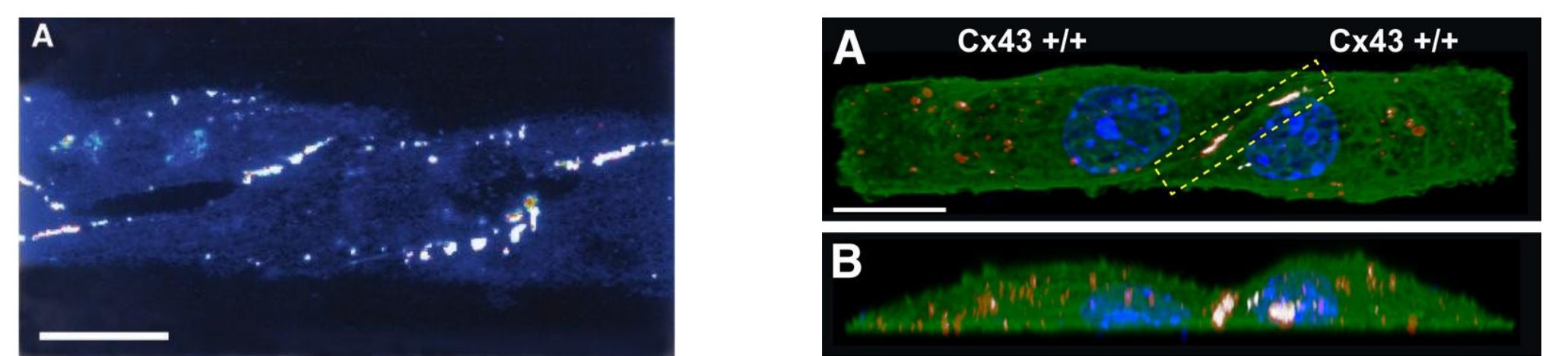

Figure : Immunohistochemical analysis of $\mathrm{C} \times 43$.

Left: $\operatorname{Bar}=10 \mu m$. (Beauchamp, 2004) Right: top view(A), lateral view(B). Bar $=5 \mu m$. (Beauchamp, 2012)

- What about electrical behaviour?

- The dual voltage patch clamp

- Non-linear behaviour

- Time dependence

- Dependent on connexin

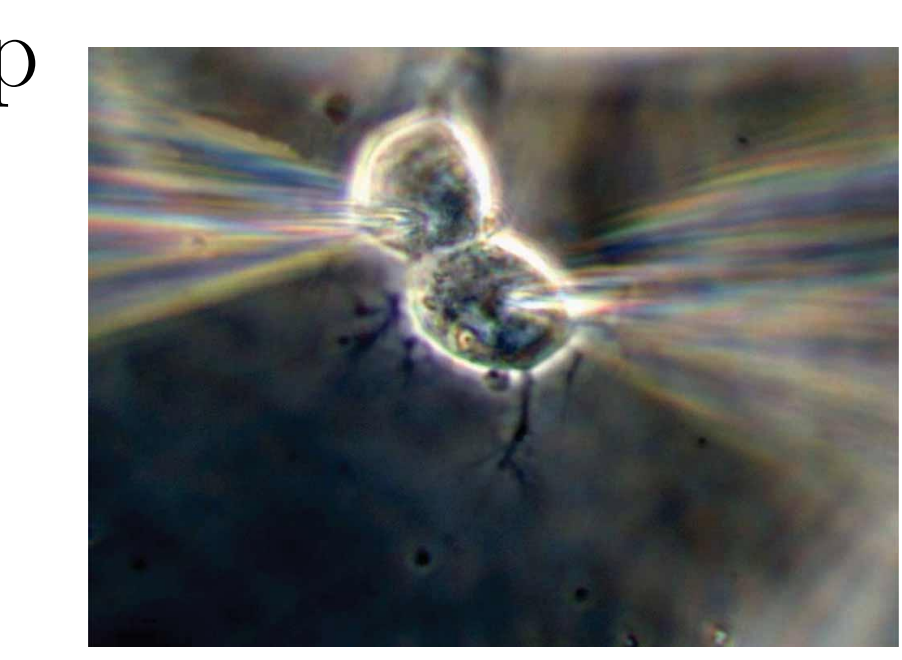
arrangement.
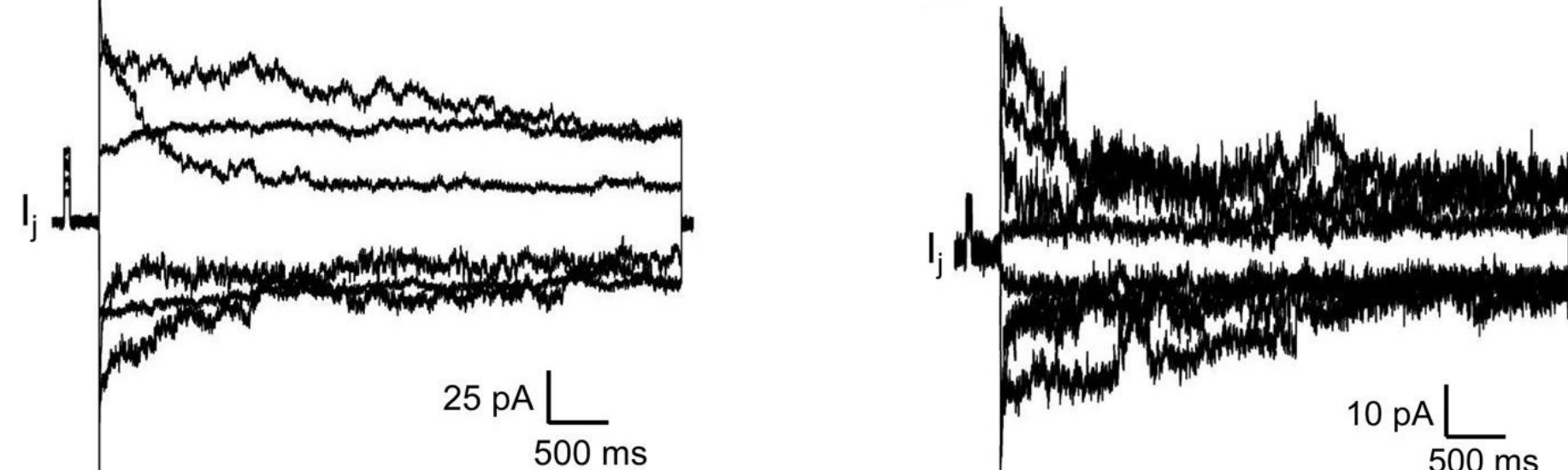

Figure: GJ currents in time, fixed $V_{j}$. Left: Homotypic

Cx43/Cx43 cell pairs. Right: Cx43KO/Cx43KO cell pairs

\section{Macroscopic effects}

- Primary cultures of $\mathrm{Cx} 43$ and $\mathrm{Cx} 43 \mathrm{KO}$ ventricular myocytes

- Macroscopic velocity calculated from the difference in activation times
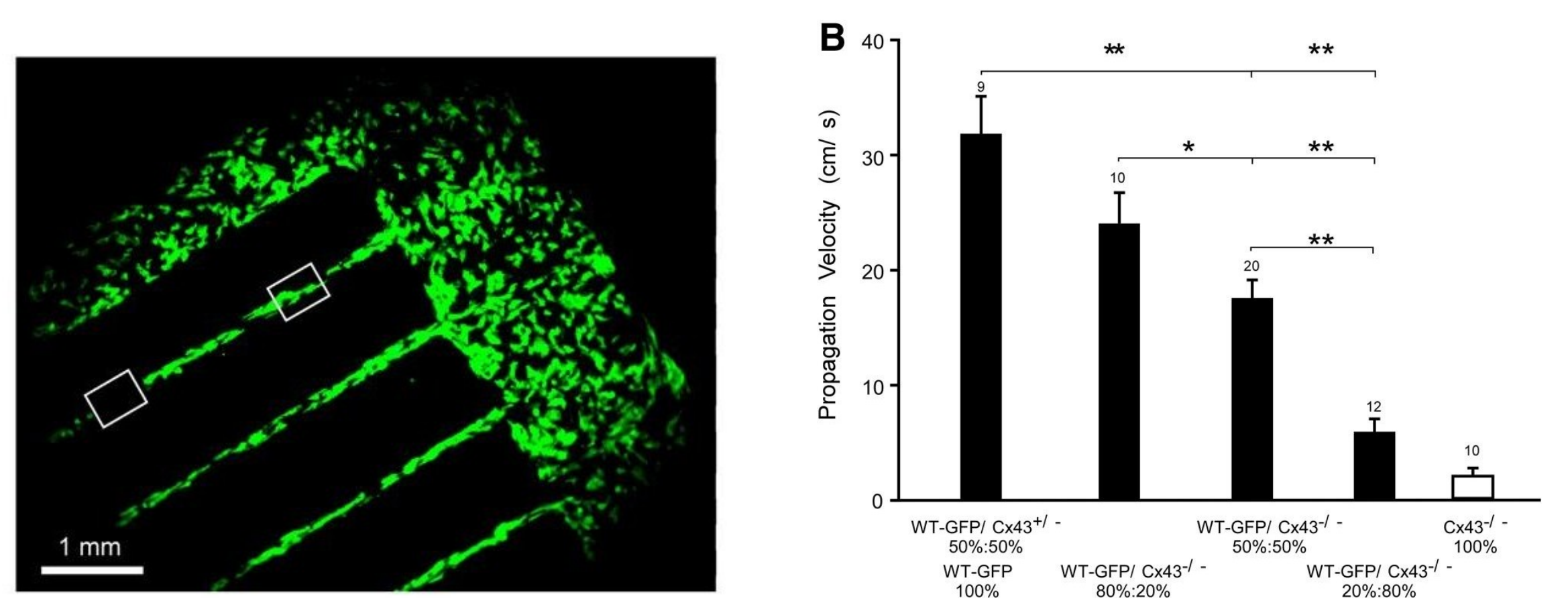

Figure : Left: A mixed patterned cell culture at low magnification. Right: Decrease in velocity of propagation w.r.t. presence of $\mathrm{C} \times 43$ cells.

\section{Non linear GJ model - OD}

- GJ current:

$$
I_{j}=G_{j}\left(t, V_{j}\right) V_{j}
$$

where:

- $V_{j}$ transjunctional voltage.

- Conductance: $G_{j}\left(t, V_{j}\right)=g_{j, 0} g_{j}\left(t, V_{j}\right)$

- The amplitude of the junctional conductance:

$g_{j, 0}=68 n S$ for $\mathrm{Cx} 43$ cells, i.e. $g_{j, 0}=2 n S$ for $\mathrm{Cx} 43 \mathrm{KO}$

- Gating variable: $g_{j}=g_{j}\left(t, V_{j}\right)$

$$
\frac{d g_{j}}{d t}=\frac{g_{\infty}\left(V_{j}\right)-g_{j}}{\tau_{\infty}\left(V_{j}\right)}
$$

- Fit experimental data to find normalised $g_{\infty}\left(V_{j}\right)$

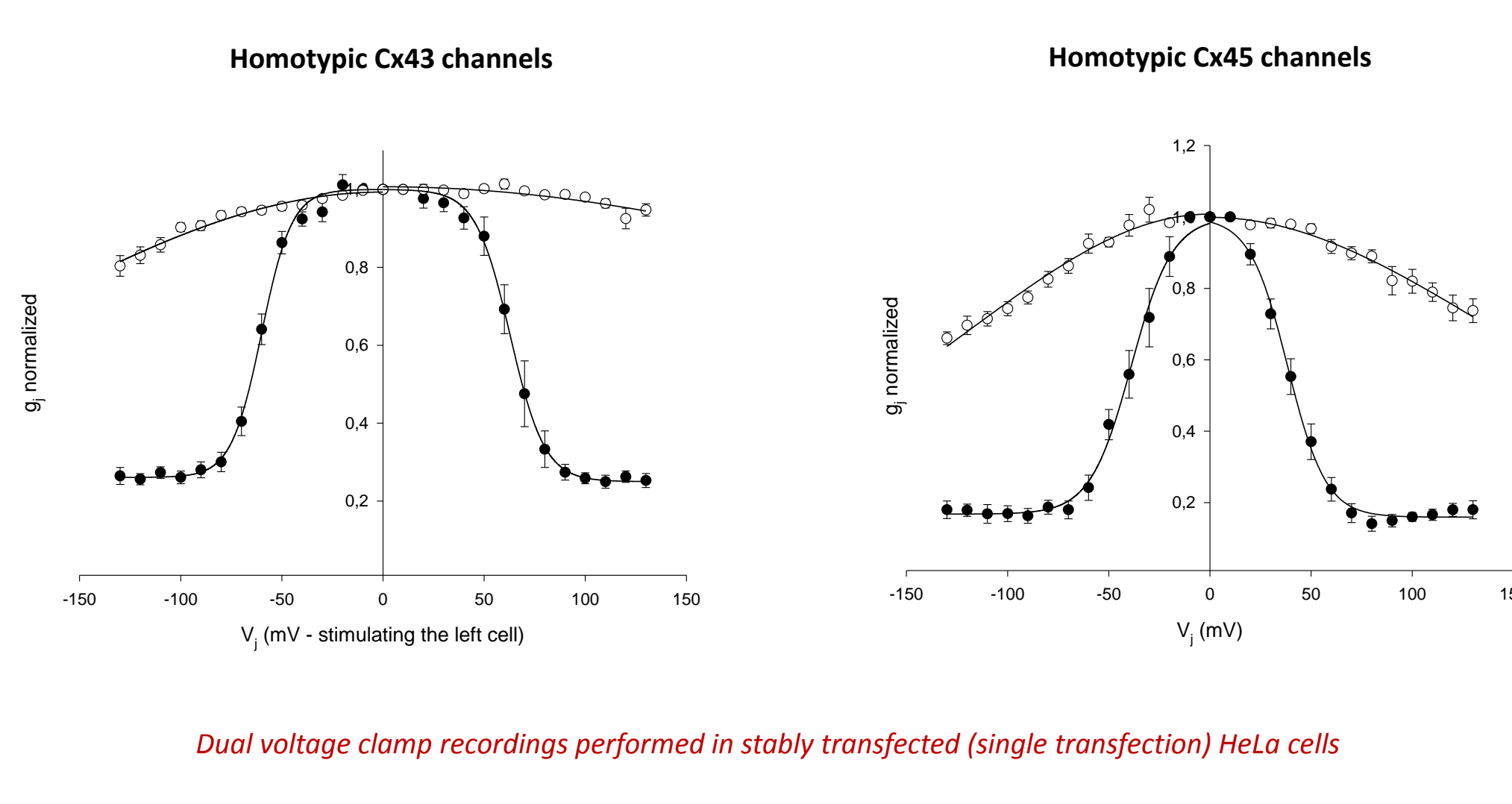

- Fit experimental data to find $\tau_{\infty}\left(V_{j}\right)$
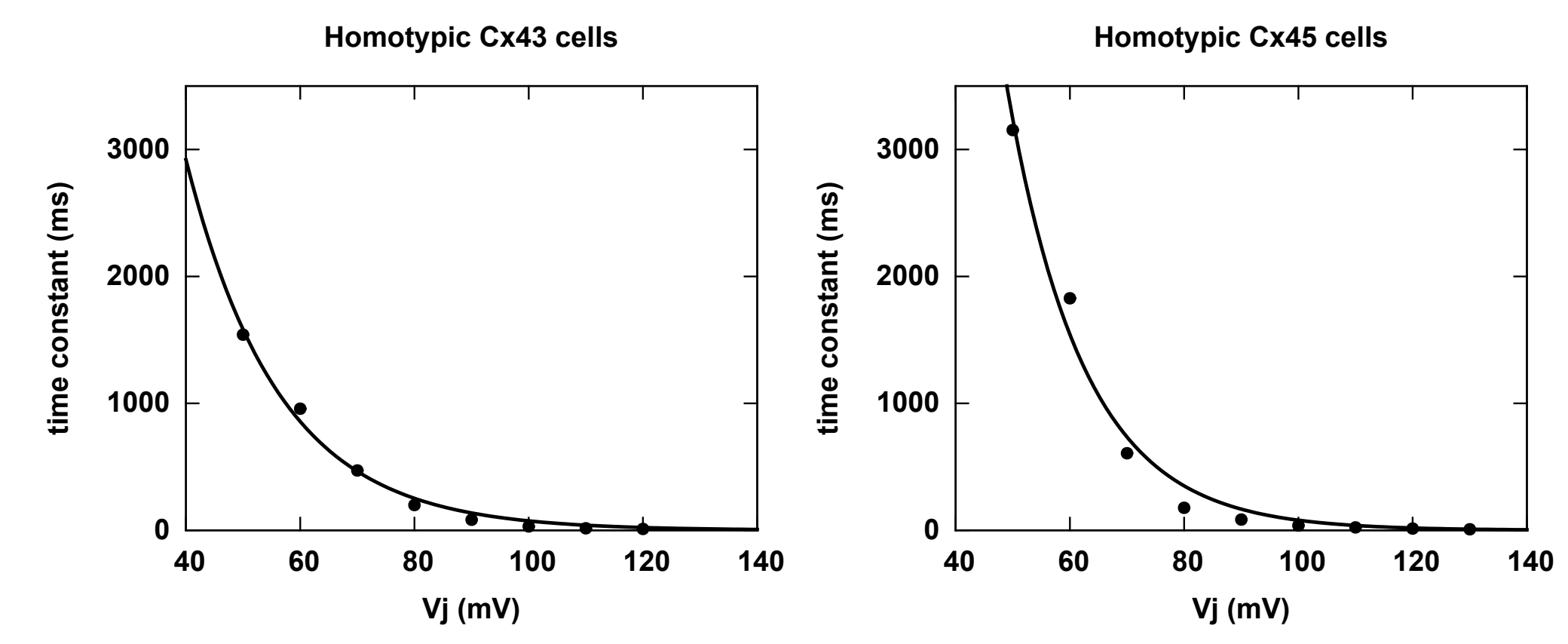

\section{Numerical simulation}

- Assume uniform distribution of GJ channels over given area (see 2D model)
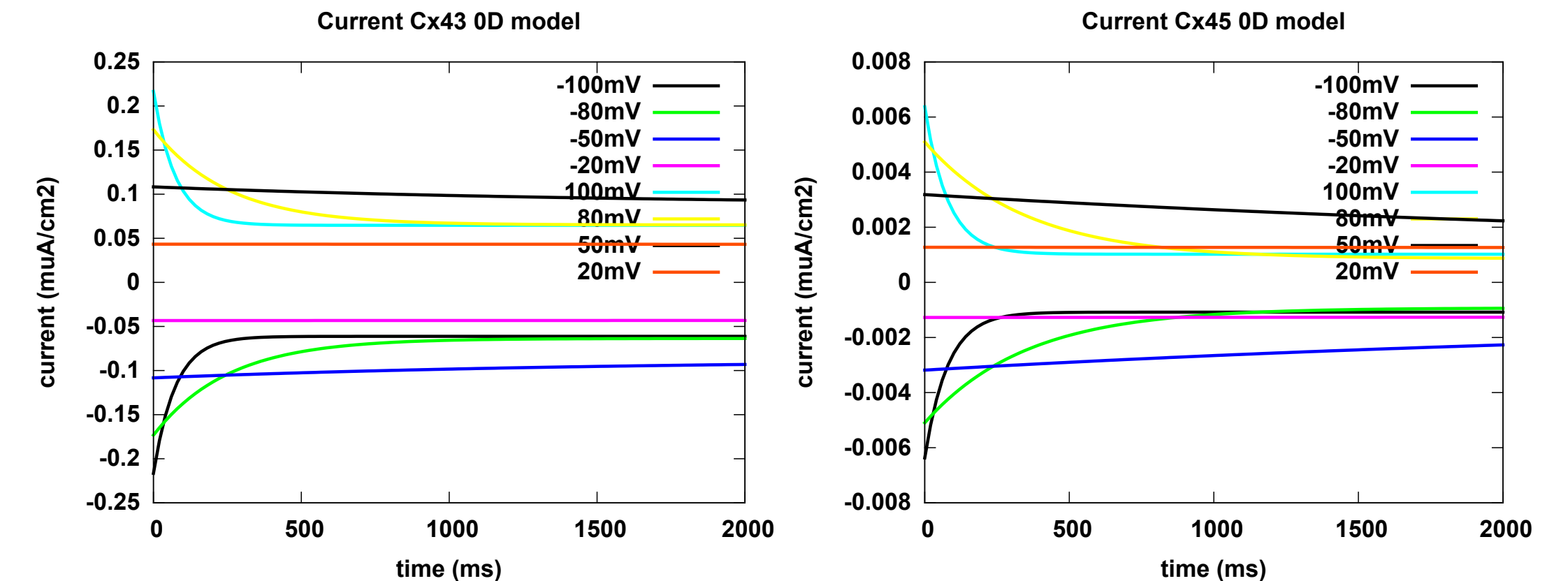

Figure: Simulated GJ current per unit area w.r.t. the time for the fixed $V_{j}$

\section{Assumptions}

- Use only homotypic Cx43 and Cx45 GJ channels.

- GJ channels are at the perimeters of the cells, on the membrane.

- The rest of the membrane has only ionic channels. Use Beeler Reuter ionic model.

\section{D microscopic model}

$\Gamma_{\text {app }} \mid \Omega$

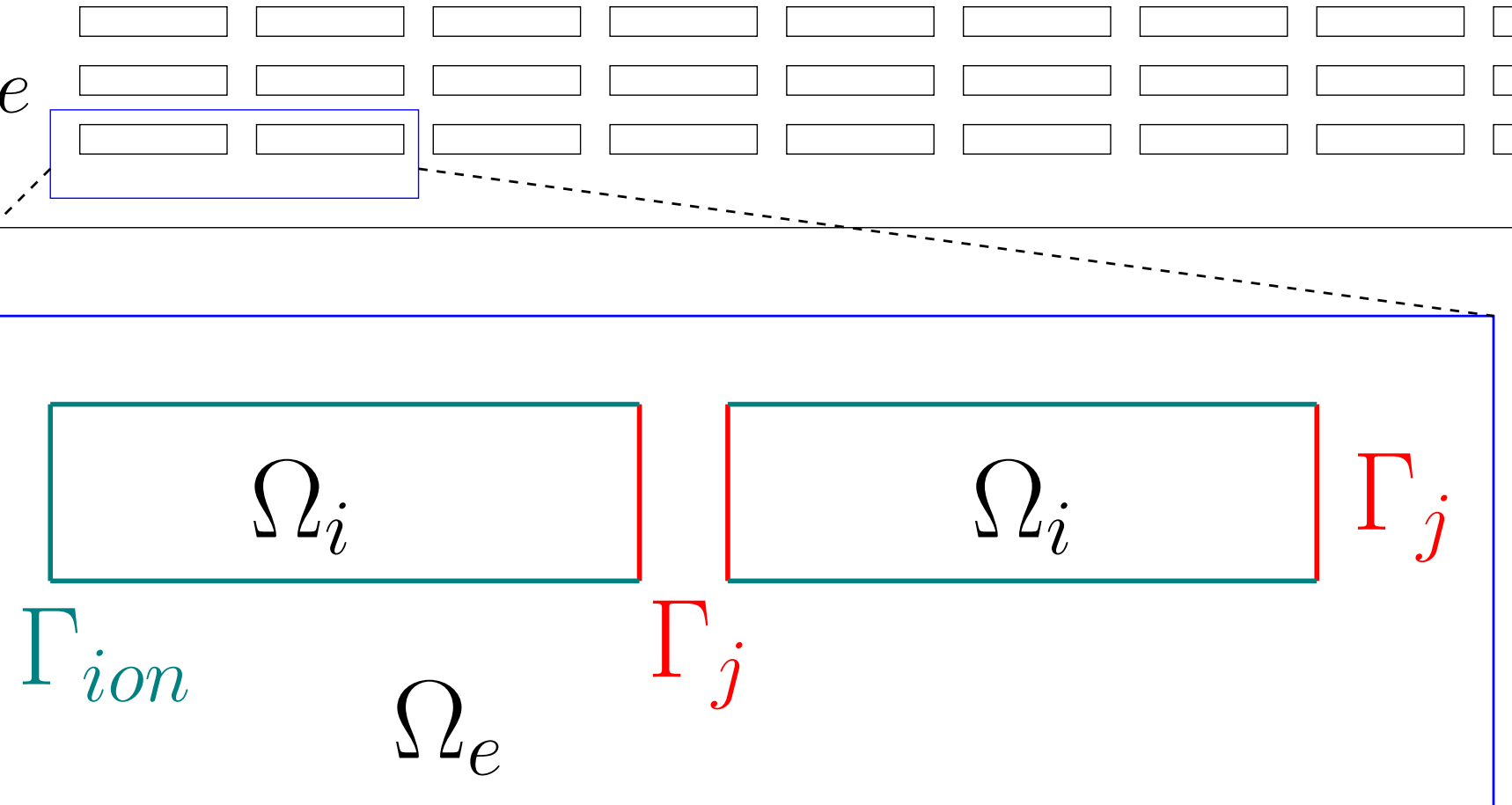

Main problem:

$$
\begin{aligned}
\sigma^{i} \Delta u_{i} & =0, & & \text { in } \Omega_{i}, \\
\sigma^{e} \Delta u_{e} & =0, & & \text { in } \Omega_{e} .
\end{aligned}
$$

Ionic model:

$$
\begin{aligned}
\partial_{t} V_{m}+I_{i o n}\left(V_{m}, \mathbf{h}\right) & =-\sigma_{i} \nabla u_{i} \cdot \mathbf{n}, \\
\partial_{t} V_{m}+I_{i o n}\left(V_{m}, \mathbf{h}\right) & =-\sigma_{e} \nabla u_{e} \cdot \mathbf{n}, \\
\partial_{t} \mathbf{h} & =f_{\text {ion }}\left(V_{j}, \mathbf{h}\right),
\end{aligned}
$$

GJ model:

$$
\begin{aligned}
G_{j}\left(V_{j}, g_{j}\right) \cdot V_{j} & =-\sigma_{i} \nabla u_{i} \cdot \mathbf{n}, \\
\partial_{t} g_{j} & =f_{j}\left(V_{m}, g_{j}\right),
\end{aligned}
$$

Boundary conditions and stimulus:

$$
\begin{array}{rlrl}
\sigma_{e} \nabla u_{e} \cdot \mathbf{n}=0, & & \text { on } \partial \Omega_{e} \backslash \Gamma_{i o n}, \\
u_{e} & =0, & & \text { on } \Gamma_{g r}, \\
\text { for } t \in\left[t_{0}, t_{0}+t_{s t i m}\right], & & \\
u_{e}=U_{a p p}, & & \text { on } \Gamma_{a p p} .
\end{array}
$$

- $\sigma_{i}, \sigma_{e}$ intra and extracellular conductivities

- $\mathbf{h}$ gating variables for ionic model

- $V_{m}=u_{i}-u_{e}$ transmembrane potential

- $V_{j}=\left[u_{i}\right]$ transjunctional potential

Numerical analysis - 2D test case

- Domain: $2 \times 1$ cells, cell size $100 \times 20 \mu m$, distance $1 \mu m$. Mesh and time step: $d x=1 \mu m, d t=0.02 m s$. - BR ionic model. Semi-implicit time scheme. FEM. Iterative method. Test: no gap junctions.

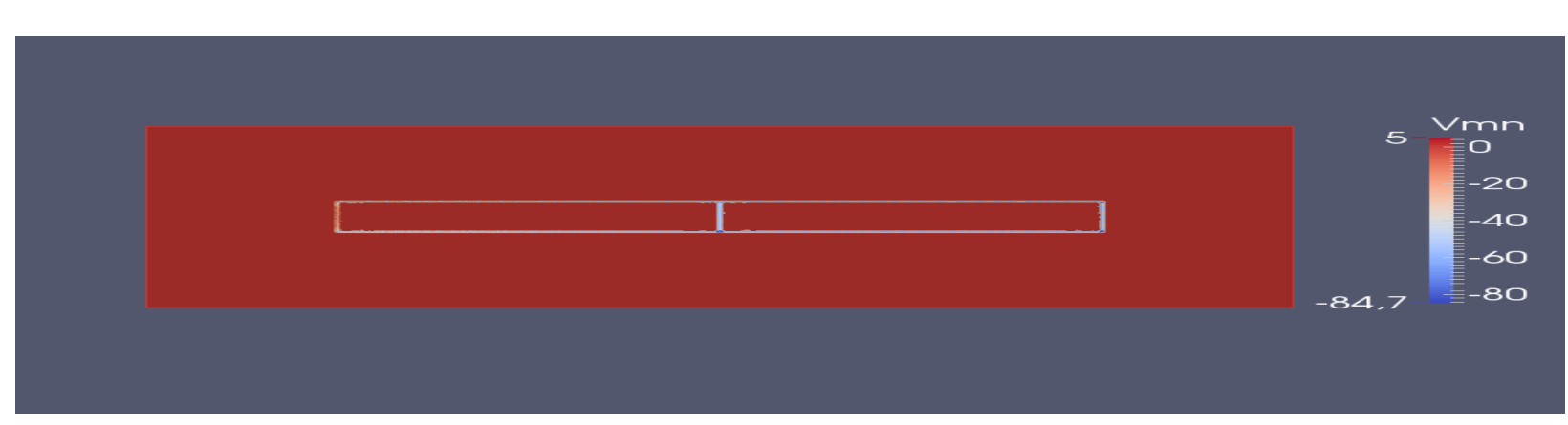

(a) time: $0.0 \mathrm{~ms}$

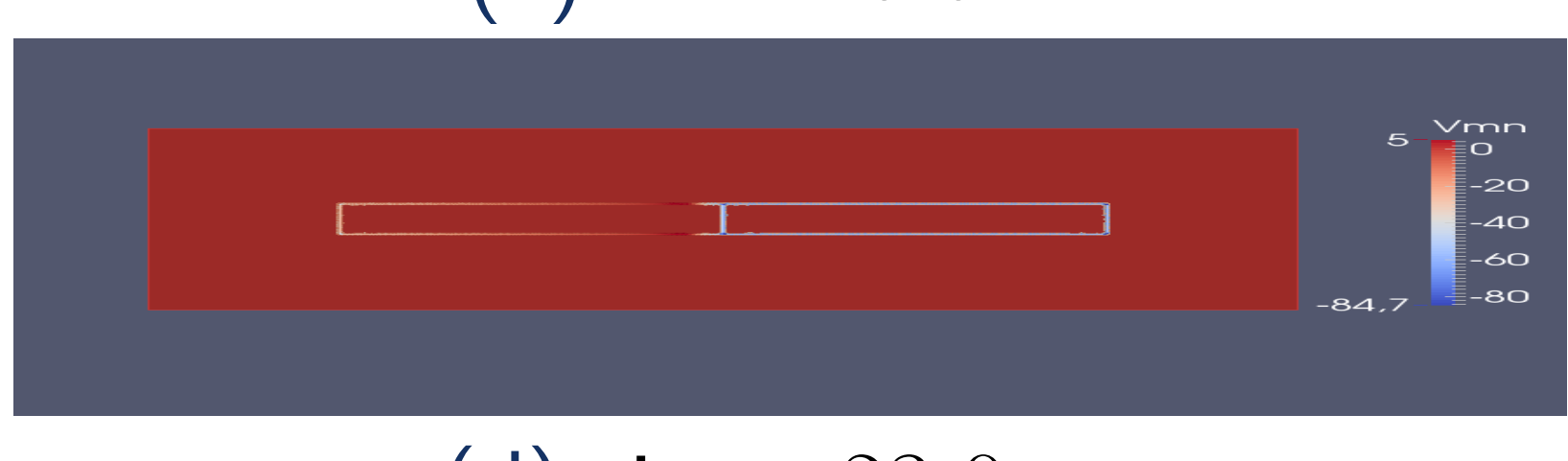

(d) time: $23.0 \mathrm{~ms}$

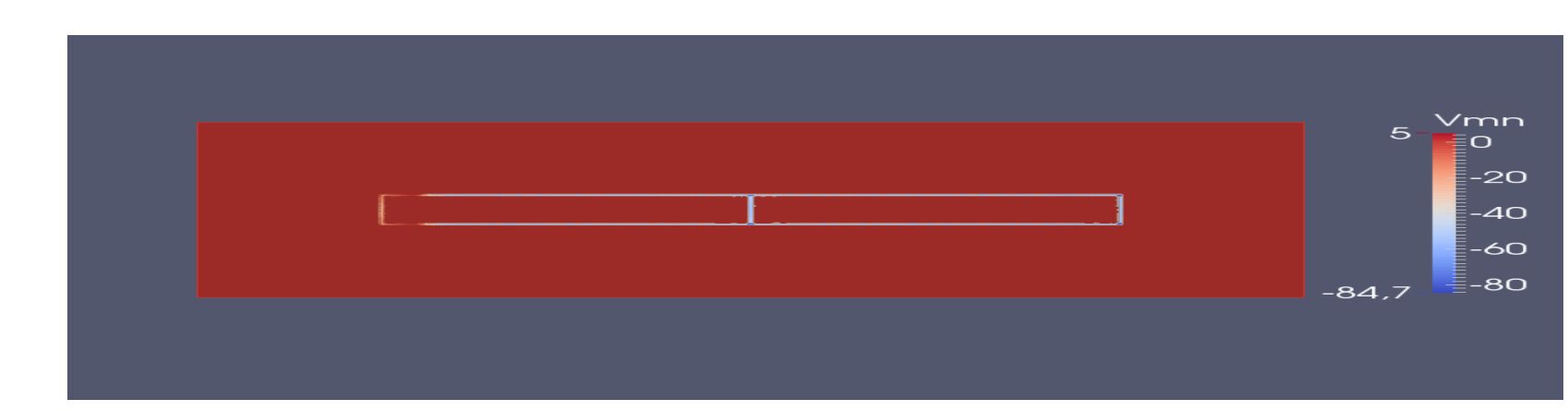

(b) time: $5.0 \mathrm{~ms}$

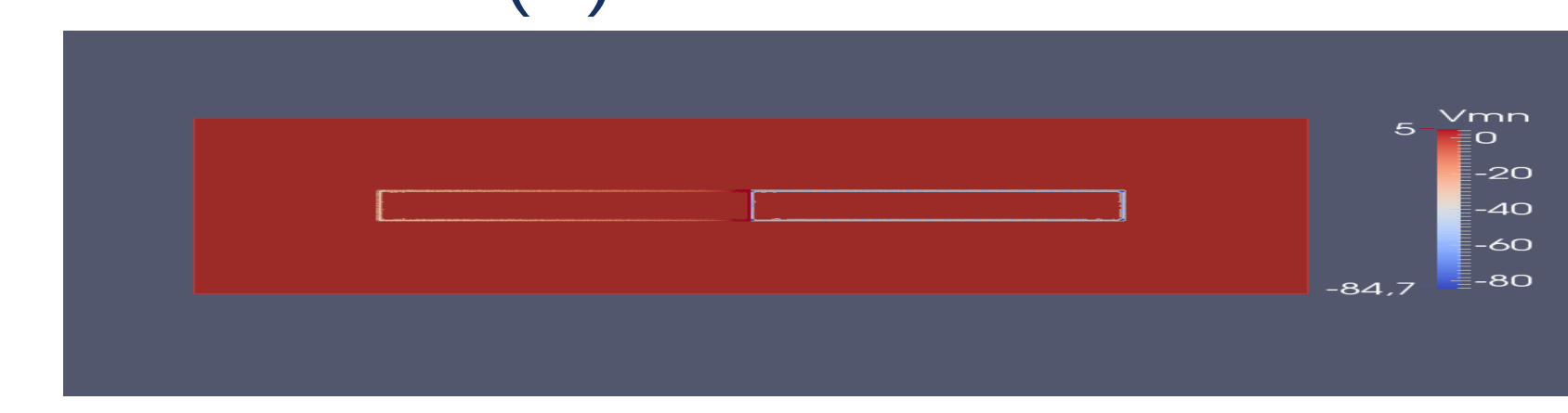

(e) time: $27.0 \mathrm{~ms}$

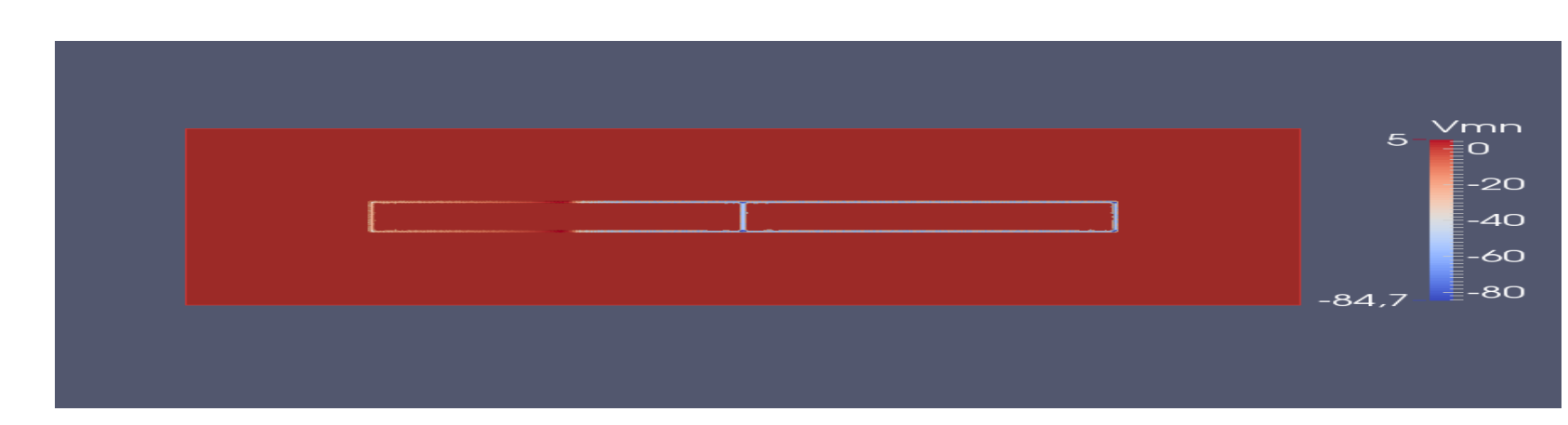

(c) time: $15.0 \mathrm{~ms}$

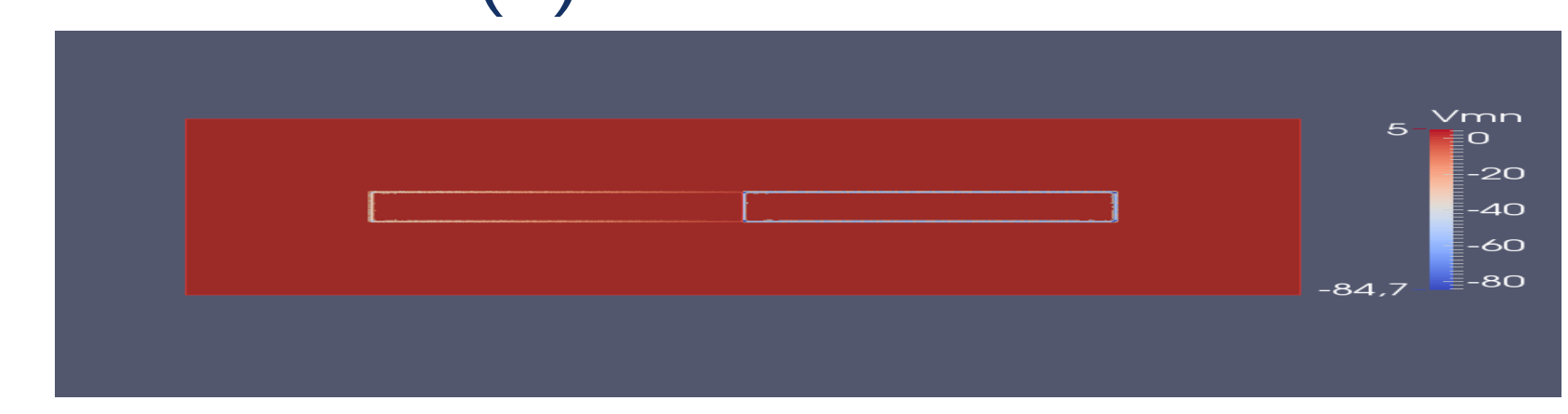

(f) time: $35.0 \mathrm{~ms}$
On going work

- Current observations: without GJ there is no AP propagation from cell to cell.

- To be tested: finer mesh, smaller cell distances.

- Include different types of GJCs on larger domains.

- Compare velocities with the experimental observations

Future work:

- Move to homogenised model
References
1] Beauchamp et al. Circulation research 95.2 (2004): 170-178. [2] Beauchamp et al. Circulation research 110.11 (2012): $1445-1453$

[3] del Corsso et al, Nature protocols 1.4 (2006): 1799-1809.

[4] Desplantez et al. Pflugers Arch. 2004 Jul;448(4):363-75

[5] Desplantez et al. J Membr Biol. 2007 Aug;218(1-3):13-28

[6] L Harris. Quarterly reviews of biophysics 34.03 (2001): 325-472.

[7] Hand and Peskin. Bulletin of mathematical biology 72.6 (2010): 1408-1424. 